http://jmscr.igmpublication.org/home/ ISSN (e)-2347-176x ISSN (p) 2455-0450

crossref DOI: https://dx.doi.org/10.18535/jmscr/v8i1.122

\title{
Prevalence of pulmonary and extra-pulmonary tuberculosis among HIV patients receiving ART at tertiary care centre
}

\author{
Authors \\ Dr Hemant Kumar ${ }^{1}$, Dr Utkarsh Kumar Srivastava ${ }^{2}$, Dr Manoj Kumar Pandey ${ }^{3}$, \\ Dr Ajay Kumar Verma ${ }^{4}$, Dr Rishabh Chaudhary ${ }^{5}$, Dr Arvind Kumar Singh ${ }^{6}$ \\ ${ }^{1}$ Assistant Professor, Department of Respiratory Medicine, Dr. Ram ManoharLohia Institute of Medical \\ Sciences, Lucknow, UP. \\ ${ }^{2}$ Assistant Professor, Mayo Institute of Medical Sciences, Barabanki, UP \\ ${ }^{3}$ Senior Resident, Department of Respiratory Medicine, Dr. Ram ManoharLohia Institute of Medical \\ Sciences, Lucknow, UP. \\ ${ }^{4}$ Additional Professor, Department of Respiratory Medicine, King George Medical University, Lucknow \\ ${ }^{5}$ Junior Resident, Department of Respiratory Medicine, Dr. Ram ManoharLohia Institute of Medical \\ Sciences, Lucknow, UP. \\ ${ }^{6}$ Associate Professor, Department of Community Medicine, Dr. Ram Manohar Lohia Institute of Medical \\ Sciences, Lucknow, UP. \\ *Corresponding Author \\ Dr Utkarsh Kumar Srivastava \\ Assistant Prof. Respiratory Medicine, Mayo Institute of Medical Sciences, Barabanki, UP, India
}

\section{Introduction}

India has the world's highest burden of tuberculosis (TB) and third largest number of people living with HIV in the world; it also ranks third in the world for HIV-associated TB. While TB is endemic across India, the HIV epidemic is concentrated in six out of all states and union territories in the country: Andhra Pradesh, Karnataka, Maharashtra, Tamil Nadu, Manipur and Nagaland. More than $75 \%$ patients with HIVassociated TB are from these six states mentioned above. About 87,000 people in India are estimated to be HIV-TB co-infected in 2017, with the national average for HIV prevalence among incident $\mathrm{TB}$ cases at $5 \%{ }^{(1)}$. It is recognized that HIV and TB make for a fatal combination with extremely high death rates $(15-18 \%)$ reported among HIV infected TB cases notified under the Revised National Tuberculosis Control Programme (RNTCP). Further even among cured TB cases with HIV infection, the risk of recurrent TB either drug sensitive or drug resistant are quite high. Overall, TB is estimated to cause about $25 \%$ of all deaths among PLHIV in India ${ }^{(2)}$. People with HIV and TB infection are much more likely to develop active TB. Each case of TB-HIV coinfection and/or drug-resistant tuberculosis severely aggravates the global TB situation. TB is a leading cause of death in HIV-infected persons, and HIV infection is the most potent risk factor for developing active TB disease from a latent TB infection $^{(3)}$. In contrast to western countries, where Pneumocystis jiroveci pneumonia was the commonest HIV-associated illness ${ }^{(4)}$, in 
developing countries TB is the most common lifethreatening opportunistic infection (OI) in patients with HIV/AIDS with about 25 to 65 per cent patients with HIV/AIDS having tuberculosis of any organ ${ }^{(5)}$. Clinical presentation of TB in HIVinfected individuals depends on the level of immunosuppression resulting from HIV infection. In patients with relatively intact immune function (CD4+ count > 200/mm3), pulmonary TB (PTB) is more frequently seen and as immunosuppression progresses, EPTB becomes increasingly common ${ }^{(6)}$.

\section{Materials and Methods}

The present study was a retrospective observation study done to calculate the prevalence of tuberculosis (pulmonary and extra pulmonary) in HIV patients at tertiary care ART centre.

\section{Study area}

The study was conducted in the department of Respiratory Medicine, Ram Manohar Lohia Institute of Medical Sciences, a tertiary care hospital and the data was collected from ART centre of the institute.

\section{Study population and Duration of study}

Total 438 patients of HIV registered at ART centre and were on antiretroviral therapy, enrolled for study after taking ethical approval from the ethical committee of the institute. Data for this study was obtained from previous one year enrolled HIV patients.

\section{Method}

The diagnosis of pulmonary tuberculosis (PTB) was based on Technical and Operational Guidelines for TB Control in India 2016. The diagnosis of extra pulmonary tuberculosis (EPTB) was based on Index-TB guideline 2016.

Statistical Analysis: The data was collected on a pre-designed schedule and entered in to Microsoft Excel (R). The Continuous variables were reported as mean and SD, and nominal/ Categorical variables were reported as percentage. The association between nominal and categorical variables was tested using chi-square test and the difference in means for continuous variables was tested using Analysis of Variance (ANOVA). P value of $<0.05$ were considered as statistically significant.

\section{Result}

Total 438 patients of HIV were investigated for tuberculosis out of which 120 diagnosed with tuberculosis, so the prevalence of tuberculosis in HIV patient was $27.4 \%$. Among 120 patients of tuberculosis 71 were suffering from pulmonary tuberculosis with prevalence of $16.2 \%$ (out of 438 patients) and 49 were from extra pulmonary tuberculosis with prevalence of $11.2 \%$ (out of 438 patients). Thus in our study pulmonary TB is more prevalent than extra pulmonary TB among HIV patients. Among Extra pulmonary TB the prevalence of lymph node $\mathrm{TB}$, abdominal $\mathrm{TB}$, Pleural TB and Neurological TB were $28.6 \%$, $28.6 \%, 24.5 \%$ and 18.4 respectively (Figure 1).

Figure 1 Site of tuberculosis

\section{Site of Tuberculosis}

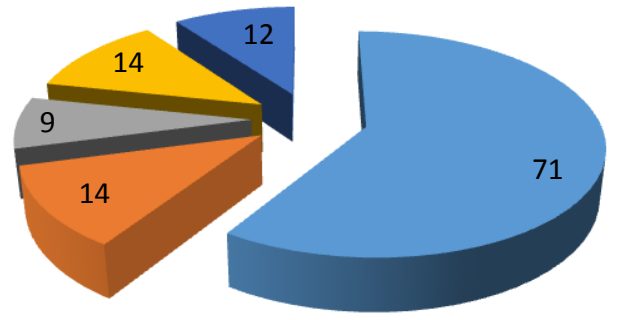

- Pulmonary TB

Abdominal TB

- Neurological TB

- Lymph node TB

n Pleural TB 
Out of 120 patients of TB-HIV 85 were in male group and 35 in female group. Among 85 male patients of TB 51were found to be in pulmonary TB group while 34 in extra pulmonary groups with highest number of patients of lymph node TB (11 patients). Among 35 female patients of TB 20 were found to be in pulmonary TB group while 15 in extra pulmonary group with highest number of patients of neurological TB (6 patients). All form of TB either pulmonary or extra pulmonary were more common in males except neurological TB which was more common in female (6 in females and 3 in males).In table Prevalence of pulmonary tuberculosis, abdominal tuberculosis, neurological tuberculosis, lymph node tuberculosis and pleural tuberculosis in male is $60 \%, 11.8 \%, 3.5 \%, 13 \%$ and $11.8 \%$ respectively; In female $57 \%, 11.4 \%$, $17 \%, 8.6 \%$ and $5.7 \%$ respectively. No significant association of site of tuberculosis in male and female in HIV patients ( $\mathrm{p}$ value 0.113) (Table1).

Table 1 Gender wise distribution of TB

\begin{tabular}{|l|c|c|c|c|c|c|c|}
\hline Sex & PTB & Abdominal & Neurological & $\begin{array}{c}\text { Lymph- } \\
\text { node }\end{array}$ & Pleural TB & Total & P value \\
\hline Male & $51(60)$ & $10(11.8)$ & $3(3.5)$ & $11(13)$ & $10(11.8)$ & $85(100)$ & \\
\hline Female & $20(57)$ & $4(11.4)$ & $6(17)$ & $3(8.6)$ & $2(5.7)$ & $35(100)$ & 0.113 \\
\hline Total & $71(59)$ & $14(11.7)$ & $9(7.5)$ & $14(11.7)$ & $12(10)$ & $120(100)$ & \\
\hline
\end{tabular}

Mean age of Pulmonary TB, abdominal TB, Neurological TB, Lymph node TB and Pleural TB is $33.4,40.2,31,35.9,38.2$ and 34.8 respectively. On way ANOVA was performed to see any difference in mean age of presentation of different site of Tuberculosis and it was found to be statistically non-significant $(\mathrm{P}=0.058)$. In HIV patients, Prevalence of Tuberculosis was high in age group of 21-40 i.e 79 patients and minimum prevalence of tuberculosis was in age group of $>60$ years i.e. 4 patients out of 120 patients. However, association between age group and site of tuberculosis was found to be statically nonsignificant $(\mathrm{P}=0.146)$ (Table2 and 3).

Table 2 Distribution of site of Tuberculosis by age group among HIV patients

\begin{tabular}{|l|c|c|c|c|c|c|c|}
\hline $\begin{array}{l}\text { Age } \\
\text { Group }\end{array}$ & PTB & Abdominal & Neurological & Lymph node & Pleural TB & Total & $\begin{array}{c}\text { P } \\
\text { value }\end{array}$ \\
\hline$<=20$ & $6(66.7)$ & $1(11.1)$ & $0(0)$ & $2(2)$ & $0(0)$ & $9(100)$ & \\
\hline $21-40$ & $50(63.3)$ & $6(7.6)$ & $9(11.4)$ & $7(8.9)$ & $7(8.9)$ & $79(100)$ \\
\hline $41-60$ & $13(46.4)$ & $6(21.4)$ & $0(0)$ & $5(17.9)$ & $4(14.3)$ & $28(100)$ \\
\hline$>60$ & $2(50)$ & $1(25)$ & $0(0)$ & $0(0)$ & $1(25)$ & $4(100)$ \\
\hline Total & $71(59.2)$ & $14(11.7)$ & $9(7.5)$ & $14(11.7)$ & $12(10)$ & $120(100)$ \\
\hline
\end{tabular}

Table 3 Prevalence of TB and EPTB

\begin{tabular}{|l|c|c|c|}
\hline Site of TB & N & Mean Age $( \pm$ SD $)$ & \multirow{2}{*}{ P value } \\
\cline { 1 - 3 } Pulmonary TB & 71 & $33.4( \pm 11.6)$ & \multirow{2}{*}{0.058} \\
\cline { 1 - 3 } Abdominal TB & 14 & $40.2( \pm 12.4)$ & \\
\cline { 1 - 3 } Neurological TB & 9 & $31( \pm 4.9)$ & \\
\cline { 1 - 3 } & 14 & $35.9( \pm 14.7)$ & \\
\cline { 1 - 3 } Pleural TB & 12 & $38.2( \pm 13.6)$ & \\
\hline Total & 120 & $34.8( \pm 12.1)$ & \\
\hline
\end{tabular}

\section{Discussion}

TB is a leading cause of morbidity and mortality in patients with HIV/AIDS. HIV-TB are also complexly linked to malnutrition, unemployment, alcoholism, drug abuse, poverty and homelessness. The direct and indirect costs of illness due to TB and HIV are massive, estimated to be more than 30 percent of the annual household income in developing countries and have a catastrophic impact on the economy in the developing world ${ }^{(7)}$. HIV infection is the strongest of all known risk factors for the development of 
TB. HIV-infected persons are at markedly increased risk for progressive disease following primary TB infection ${ }^{(8)}$, as well as reactivation of latent tuberculosis infection (LTBI). HIV infection also increases the risk of subsequent episodes of TB from exogenous reinfection. The estimated annual risk of reactivation among those coinfected with HIV and TB is about 5 to 8 per cent with a cumulative lifetime risk of 30 per cent or more compared to a cumulative lifetime risk of 5 to 10 per cent in HIV-negative adult patients ${ }^{(9)}$.

Th1 type immune response characterised by adequate cell-mediated immunity is the crucial host defence against $M$. tuberculosis ${ }^{(10)}$. HIV infection primarily affects those components of host immune response responsible for cellmediated immunity. Thus in HIV infected individuals with LTBI, the fine balance between M. tuberculosis and the host immunity gets shifted in favour of the former, resulting in reactivation (11). Moreover, the infection is poorly contained following reactivation, resulting in widespread dissemination causing extra pulmonary disease. This is corroborated by experimental findings that when peripheral blood lymphocytes of patients with HIV-TB are exposed to M. tuberculosis invitro, they produce decreased amounts of Th1 type cytokines, as compared with HIV-negative patients with $\mathrm{TB}^{(12)}$.

In this study, out of the total 438 HIV positive patients, who attended the ART clinic and investigated for tuberculosis, $120(27.4 \%)$ had HIV/TB co- infection and remaining 318 (72.6\%) were HIV positive alone. Similarly, a study done by Padyana et ll $^{(13)}$ at a tertiary care hospital of South India, among 200 HIV positive patients, showed that $54(27 \%)$ patients had HIV/TB co- infection and remaining 146 (73\%) were HIV positive alone.

In our study the prevalence of pulmonary TB was higher as compare to EPTB in HIV infected patients $(16.2 \%$ vs $11.2 \%)$, this is concordant with study done by zumla et al in $2000^{(6)}$. Study has shown that the clinical presentation of TB in HIV-infected individuals depends on the level of immunosuppression resulting from HIV infection. In patients with relatively intact immune function (CD4+ count > 200/mm3), pulmonary TB (PTB) is more frequently seen than EPTB.

Abdominal TB and lymph node TB was the most common presentation of EPTB in our study (14 patients in each group) followed by pleural (12 patients) and neurological TB (9 patients) respectively. Worldwide lymph node $\mathrm{TB}$ is the most common form of $\mathrm{EPTB}^{(14)}$ found in studies from Ethiopia, Canada, Turkey, Nepal and Indian ${ }^{(15)}$. In our study abdominal TB cases was present in equal frequency with lymph node possibly because most of case was referred to ART centre from medicine department. All form of EPTB in our study was more frequently seen in males except neurological TB this was possibly due to, out of 49 patients of EPTB, 34 patients were males and rest 15 were female patients.

Limitation: CD4 Count and Site of Tuberculosis were not measured.

\section{Conflict of interest: None}

\section{References}

1. WHO. 2017. Global TB Report.

2. NACO. 2013. National Framework for Joint HIV/TB Collaborative Activities. MoHFW, Government of India.

3. Tb India 2011, Revised National $\mathrm{Tb}$ Control Programme: Government of India Annual Status Report. Chapter 1:Tuberculosis Burden; 2011.

4. Mocroft A, Youle M, Morcinek J, Sabin CA, Gazzard B, Johnson MA, et al. Survival after diagnosis of AIDS: a prospective observational study of 2625 patients. Royal Free/Chelsea and Westminster Hospitals Collaborative Group. BMJ 1997; 314 : 409-13.

5. Sharma SK, Kadhiravan T, Banga A, Goyal T, Bhatia I, Saha PK. Spectrum of clinical disease in a cohort of 135 hospitalised HIV-infected patients from north India. BMC Infect Dis 2004; 4 : 52. 
6. Zumla A, Malon P, Henderson J, Grange JM. Impact of HIV infection on tuberculosis. Postgrad Med J 2000; 76: 259-68.

7. Russell S. The economic burden of illness for households in developing countries: a review of studies focusing onmalaria, tuberculosis, and human immunedeficiency virus/ acquired immunedeficiency syndrome. Am J Trop Med Hyg 2004; $71:$ 147-55.

8. Liberato IR, de Albuquerque Mde F, Campelo AR, de Melo HR. Characteristics of pulmonary tuberculosis in HIVseropositive and seronegative patients in a northeastern region of Brazil. Rev Soc Bras Med Trop 2004; 37 : 46-50.

9. Corbett EL, Watt CJ, Walker N, Maher D, Williams BG, Raviglione MC, et al. The growing burden of

tuberculosis: global trends and interactions with the HIV epidemic. Arch Intern Med 2003; $163: 1009-21$.

10. Schluger NW, Rom WN. The host immune response totuberculosis. Am J RespirCrit Care Med 1998; 157 :679-91.

11. FitzGerald JM, Houston S. Tuberculosis: The disease in association with HIV infection. CMAJ 1999; 161 : 47-51.

12. Subramanyam S, Hanna LE, Venkatesan P, Sankaran K, Narayanan PR, Swaminathan S. HIV alters plasma and $M$. tuberculosis-induced cytokine production in patients with tuberculosis. J Interferon Cytokine Res 2004; 24 :101-6.

13. Padyana M, Bhat RV, Dinesha M, Nawaz A. HIV- tuberculosis: A study of chest $\mathrm{X}$ - Ray patterns in relation to CD4 count.N Am J Med Sci2012;4:221- 5.
14. Prakasha SR, Suresh G, D`sa IP, Shetty SS, Kumar SG. Mapping the pattern and trends of extra pulmonary tuberculosis. J Global Infect Dis 2013;5:54-9.

15. Rai DK, Bisht RS, Sikarwar V, Upadhyay SK. Clinicoepidemiological trends of tuberculosis in garhwal region. IOSR Journal of Pharmacy. 2012;2:39- 43. 